\title{
SIETE NOTAS ANDINAS PARA PENSAR LA ÉTICA
}

\author{
Luis Mujica Bermúdez
}

\begin{abstract}
Resumen:
El artículo propone siete anotaciones que provienen de las concepciones y prácticas andinas, las que buscan contribuir a la reflexión sobre el sentido que tiene la ética en estos tiempos, tomando en cuenta la lengua quechua actual. En esta perspectiva, el artículo propone que la ética (yachakuy) es una práctica reflexiva permanente que está inserta en la historia actual andina, allí donde las personas conviven con la naturaleza y hacen historia en la medida que consideran el cuidado mutuo y la responsabilidad humana como indispensables para que haya una convivencia y verdadera paz.
\end{abstract}

Palabras clave:

Ética, Mundo andino, Diversidad cultural, Responsabilidad humana. 


\title{
Seven Andean notes to think Ethics
}

\begin{abstract}
:
The article proposes seven annotations that come from Andean conceptions and practices, which seek to contribute to the reflection on the meaning that ethics has in these times, taking into account the current Quechua language. In this perspective, the article proposes that ethics (yachakuy) is a permanent reflexive practice that is inserted in the current Andean history, where people live with nature and make history to the extent that it considers mutual care and human responsibility as indispensable for a coexistence and true peace.
\end{abstract}

\section{Keywords:}

Ethics, Andean world, Cultural diversity, Human responsability.

\section{Luis Mújica Bermúdez}

Licenciado, magister y doctor en antropología por la Pontificia Universidad Católica del Perú (PUCP). Docente del Departamento de Ciencias Sociales de la PUPC e investigador del Grupo Interculturalidad y Ambiente (GIyA) del INTE-PUCP. Investigador de la Red Internacional de Estudios Interculturales (RIDEI).

Investiga en torno a temas ambientales, conocimientos locales y la dimensión epistemológica en el mundo andino; acerca el desarrollo humano en relación con la ciudadanía y el Estado; sobre las relaciones entre culturas y la interculturalidad vinculadas a la educación intercultural bilingüe; asimismo, estudia la ética en relación con la vida política del Perú, desde una perspectiva antropológica. Entre los libros publicados podemos mencionar: Pachamama kawsan: hacia una ecología andina (2017). Poncho y sombrero, alforja y bastón: la Iglesia en Cajamarca, 1962-1992 (2005). En coautoría con otros investigadores resaltamos: Los que se quedan. Familias de emigrado de un distrito de Lima (2008); Ama usuchisqa kanapaq, runayananchikpaq. Para ser ciudadanos y no ser discriminados (2011); Redes y maletas. Capital social en familias de migrantes (2013); Qichwasimirayku: Batallas por el quechua (2014).

Correo electrónico: lmujica@pucp.pe 


\section{Presentación}

¿Se puede decir algo sobre la ética desde el mundo andino? ¿Qué elementos podrían considerarse para pensar éticamente las relaciones sociales desde las concepciones andinas? Seguramente habría más preguntas que hacer, pero aquí tan solo nos proponemos presentar algunas reflexiones con el propósito de dialogar en torno a la ética desde el punto de vista de los pobladores andinos. Las afirmaciones que se presentan - a modo de hipótesis- pueden ser consideradas para repensar las maneras de vivir en contextos sociales y culturales actuales. Consideramos al mundo andino como una realidad abierta y, en cierto sentido, una sociedad plural que con sus acciones ha ido mostrando históricamente la voluntad de adaptarse a los cambios del mundo contemporáneo. Las personas que provienen del mundo andino siguen mostrando que es posible articularse a los procesos modernos y a la vez cuestionar lo que contraviene a sus derechos. En este artículo presentamos siete notas para contribuir a la reflexión sobre la ética desde ese mundo que busca vivir los cambios pero también pensar el destino de la humanidad desde su experiencia.

\section{La ética es habitar y pensar lo vivido: yachay y yachakuy}

El ethos griego puede traducirse al quechua como yachay o tiyay ${ }^{1}$ Y Yachay significa 'habitar o vivir en algún lugar' y 'conocer o saber cómo se vive'2. La palabra tiyay significa 'estar asentado habitualmente en algún lugar' y por ello 'conocer su manera de vivir'. En cambio, yachakuy, que es la raíz yachay seguida del sufijo $k u$, indica que la acción emprendida por el sujeto recae sobre sí mismo, y se puede traducir como 'vivir-se-uno mismo', vale decir que la

\footnotetext{
1 Aquí emplearemos la grafía quechua normalizada por la Resolución Ministerial №1218-85-ED del Ministerio de Educación. La acepción elegida en cada caso es la más cercana según los contextos en la que se use.

2 Uno de los sentidos comunes y muy conocido de yachay es 'saber' o 'conocer', que luego dará paso a enseñar y aprender.
} 
persona no solo es consciente del vivir o habitar sino que también reflexiona sobre esta situación. Cuando una persona quechuahablante dice yachakunim (yo me vivo), quiere decir que sabe o conoce el sentido que tiene su actuar $\mathrm{y}$ que es consciente de lo que hace y de los resultados de las acciones que puede realizar. Para resumir, nosotros adoptamos aquí el término yachakuy para expresar la tarea de pensar sobre la manera de 'saber', 'habitar' o 'vivir' (yachay) aquí y ahora, en estos tiempos.

La ética, una constante materia de reflexión en diferentes tiempos y espacios, cuenta también con una categoría propuesta para hablar del tema en quechua ${ }^{3}$. Sin embargo, considero que en contextos concretos y cambiantes como el andino aún queda mucho por hacer para ampliar el sentido que se le puede dar a la palabra ética y su contenido. Partiendo de esta consideración, entonces, ¿qué es la ética o el yachakuy? Se trata de un conjunto de conocimientos que permiten a las personas saber, actuar y vivir reflexionando sobre su propia manera de vivir o habitar en un contexto determinado. El pensar (hamutay) hace que la persona pueda revisar su conducta y las implicancias que tienen sus acciones. Ese conocimiento es un yachakuy, una acción reflexiva que revisa las decisiones propias del individuo pero también considera las consecuencias de las acciones que suelen darse en varios campos. En este sentido, las personas «cuentan sus experiencias en la búsqueda de un camino y un tiempo nuevo», como señalan Escalante y Valderrama (1992: XXVIII) recordando los testimonios de Victoriano Tarapaki y Lusiku Ankalli, dos pobladores andinos de Cotabambas que reflexionan sus acciones como un yachakuy.

Una persona, al decir «arí, yachakunim» (sí, yo me doy cuenta de lo que hago) explicita, primero, que es consciente de su situación y condición real en la que vive; segundo, que tiene pleno conocimiento de sus aptitudes y condiciones personales; tercero, que sus acciones tienen una direccionalidad y fines determinados; y cuarto, que es responsable de las acciones que realiza y también de los resultados de esas acciones. Por ello, el término yachakuni muestra la capacidad y el poder que la persona tiene en sí misma y las posibilidades y potencialidades que encierra su acción. Las acciones pueden ser prudentes o imprudentes, pueden salvar o dañar, respectivamente. Asimismo, las acciones pueden contribuir a transformar o destruir lo que forma parte de la existencia de uno y las personas pueden ser conscientes o no de esos hechos, así como también pueden negar los hechos atribuibles para no ser sancionados por las consecuencias.

3 Estermam (2008) ha creado el neologismo ruwanasofía para indicar la ética, el cual —a nuestro modo de ver - no logra sintetizar el sentido que queremos darle a la ética en este texto. Una nota crítica sobre este tema ha sido desarrollada por Sobrevilla (2008). 
Por medio del yachakuy la persona puede contemplar qué tipo de acciones realizar y decidirse por una de ellas con la finalidad de relacionarse con los demás y con la naturaleza misma. En este plano, por ejemplo, un agricultor andino considera que habitar su lugar es un acto que implica saber relacionarse con otros: yachanakuniku (yo 'me' vivo en reciprocidad con otro). Esto supone que existe la necesidad de revisar el punto de partida de las relaciones y además considerar las consecuencias de esas relaciones en su sentido más específico. Esta manera de vivir o habitar propone una ética que invita a una acción reflexiva sobre lo que hace el ser humano en su contexto, en relación con los otros que son múltiples y que igualmente viven aquí y ahora.

La ética en el mundo andino implica un conjunto de principios y valores que orientan la conducta personal y las maneras de relacionarse con los otros y con el mundo no humano, manteniendo el respeto y la tolerancia; en suma, considerando ciertas reglas de 'convivencia' con los demás. Los principios y valores hacen de la ética una acción crítica permanente porque se trata de construir relaciones de confianza con los otros en medio de los cambios que se van produciendo en medio de la dinámica social. Aquella conducta, sin embargo, está permanentemente retada por diversas relaciones y circunstancias, incluso inesperadas, que necesitan del 'pensar' para así volver la mirada sobre las acciones realizadas y re-visarlas conscientemente; pues una postura crítica requiere de una conciencia, que es como el alma que hace del ser humano un ser pensante porque «almallanchikmi hapiwanchik runata hina [sic] (solo nuestra alma nos retiene como a humanos)» (Escalante y Valderrama 1992: 29) ${ }^{4}$.

Como se trata de conductas y de acciones humanas que buscan relacionarse con las personas y la naturaleza, estas acciones no están controladas del todo $\mathrm{y}$ esto hace que puedan generarse resultados no deseados, cuyas consecuencias pueden no ser necesariamente beneficiosas para el conjunto de los actores sociales y la naturaleza. La conducta humana tiene resultados negativos, los que se califican directamente como yanqa ruray (hacer falsamente) o waqlliy (traicionar), llullay (engañar o mentir), por citar algunos. En cambio, a las personas con conductas positivas se les dice llampu sunqu (persona prudente y tierna) o sunqusapa (prudente y noble), entre otros.

Las acciones humanas, entonces, pueden ser producto de una planificación y de decisiones concertadas o no necesariamente. Las acciones pueden ser individuales y grupales; y connotan responsabilidades que conllevan una preparación, planificación, ejecución y, también, la

4 La traducción de los autores dice a la letra: «Solo nuestra alma nos tiene como a humanos». 
consideración de las consecuencias de esas acciones. Son planificadas en la medida en que las acciones a realizarse obedecen a intereses y están vinculadas con fines u objetivos; vale decir que dichas acciones están sometidas a la selección y la elección (akllay) de medios y procedimientos. Las acciones tienen también costos previstos y otros que no lo son, las consecuencias pueden ser positivas o negativas para las partes. Sin embargo, en estos tiempos, la conducta de las personas en el mundo andino ha ido cambiando por la presencia de factores externos y la urgencia de vida en la que se va instalando un pragmatismo que busca una solución de los problemas y dificultades acorde con una mentalidad individualista.

Entonces, la ética (yachakuy) es un conocimiento para actuar racionalmente, vale decir que se trata de una manera de pensar la convivencia para volver a realizar acciones de manera razonada y controlada. Entonces, ¿qué tipo de ética está presente en el mundo andino? Esta es la pregunta que tratamos de responder con los elementos que la filosofía y las ciencias sociales nos proporcionan hoy. La reflexión sobre el comportamiento humano ha estado y está presente en todos los tiempos y en cada cultura -a su modo- buscando facilitar la convivencia entre seres humanos y con la naturaleza o el mundo que llamamos pachamama.

\section{Yo habito aquí y ahora: pachamamapi yachani}

Una vez visto qué es la ética, esta palabra nos invita a pensar que el ser humano habita un mundo cuyas coordenadas están construidas social y culturalmente de alguna forma 'diferente' en relación con otras culturas. Aquellas coordenadas conforman un espacio multidimensional y complejo, y se denomina pachamama, cuyo significado abarca las nociones de espacio, tiempo y las identidades que se forman de muchas maneras. Decir pachamamapi yachani (habito o vivo en la tierra) significa que yo pertenezco y hago historia en medio de sus cambios y vicisitudes. Pero también se podría decir pachamamapi tiyani (estoy asentado en la tierra) para mencionar que yo estoy presente aquí y existo entre un conjunto de elementos construidos por los seres humanos. La pachamama en la experiencia humana andina es la referencia inmediata para decir que el habitar en un lugar no es una mera experiencia individual sino es también una experiencia colectiva que tiene tradiciones e historias. La palabra pachamama está compuesta de pacha y mama. El primer término significa tiempo y espacio y el segundo se puede traducir como base fundamental, continente o basamento de la existencia en el tiempo y el espacio en los que incluyen las identidades diferenciadas.

El yachani andino implica una condición y una relación diádica de elementos, que en quechua se dice yanantin (Yánez 2002). El habitar en la 
pachamama no es un vivir autárquico sino un convivir con otro del que no se puede prescindir. Existen los unos y los otros implicados y vinculados de manera innegable. El otro para el uno es su yana (par) y viceversa, se trata de una realidad de la que uno no puede desprenderse; pues el aislamiento de una de las partes puede terminar destruyendo la vida misma. La vida requiere de su yanantin, vale decir que cada cual tiene su par (o su impar) sabiendo que cada parte es diferente al otro. Si alguien dice yanaywan yachani está diciendo que 'yo convivo con otro' que es diferente a uno y con el que forma una comunidad básica diádica permanente. Entonces, el aislamiento es algo que pende como una amenaza constante y que debe ser permanentemente rehecho. A la amenaza del aislamiento se le dice: chullayay o ch'ullayay (posibilidad de estar o quedarse sin pareja, aislado, abandonado). Por eso, Lusiku tomando conciencia de sus correrías por diferentes lugares y consciente de su soledad y abandono le dice a su compañero de aventuras: "[...] haku uywanchikta huñukumusunchik uywanchik uywawananchikpaq (vamos a juntar nuestros animales para que estos nos cuiden a nosotros también)» (Escalante y Valderrama 1992: 26). No es posible vivir solos (por mucho tiempo); los otros (en general) son parte constitutiva de la vida social y si esto no ocurre la maldición de la chulla kay (estar abandonado) cubrirá como un manto de fatalidad la vida personal y social.

En esta perspectiva, la ética andina propone que el yachay (vivir) tiene como punto de partida una configuración estructural de la vida con el otro o el existir: yanantin. Este término es similar a la expresión de Levinas, para quien la estructura esencial, primera, fundamental de la subjetividad es la «responsabilidad-para-con-el-otro» (1991: 89). Aunque el sentido mismo de responsabilidad será abordado más adelante, es importante señalar que el yanantin no es un habitar etéreo o virtual, sino un habitar con otro que tiene especificidades insondables. Esto quiere decir que la vida humana es fundamentalmente comunidad, vínculos, implicancias y convivencia; en resumen, ayllu. Cada individuo nace en un ayllu y es inmediatamente aylluchasqa (adoptado por una familia). En efecto, nadie ni nada - en principio- es abandonado, antes bien es adoptado como miembro de esa comunidad y convocado a ser alguien yanantin, es decir, un individuo vinculado a otro con quien hace una comunidad radicalmente ética desde el comienzo. Hoy en día, como en otras culturas, muchas mujeres andinas adoptan a niños que se quedan sin madre para su crianza y educación sin pasar por un trámite legal de adopción.

El yachanakuy significa que los seres nacemos y vivimos en un contexto interdependiente e inextricable con los otros. Por eso es posible ser yanantin (con su par) como unidad y comunidad. Los 'seres' que conforman la comunidad son visibles y no visibles; son conocidos y no conocidos; son formas concretas del existir para los seres humanos. Cada realidad trasciende su propia unidad para formar parte de relaciones múltiples y diferentes, pues 
cada cual es parte del todo. En esta realidad la relacionalidad es, entonces, un punto de partida para construir las maneras de entender el mundo que circunscribe a los pobladores andinos. El 'vivir en' es 'habitar con otros' de manera que la forma de vivir está sujeta a cambios y modificaciones de las maneras de entender el lugar donde habita; este mundo tiene múltiples posibilidades de ser visitado sin ser absorbido necesariamente.

Si el yachakuy es la forma de dar cuenta sobre lo que se hace en la vida cotidiana, entonces, el término significa para nosotros la capacidad de reflexionar sobre la propia manera de vivir en relación con otros en el marco de la condición diádica asimétrica y siempre desigual pues el mundo andino no es homogéneo, muchas de sus comunidades están relativamente aisladas, los cambios experimentados en diversos grados hacen que sus pobladores vivan nuevas situaciones de subalternización, invisibilización y 'ninguneo'. Dentro de esta perspectiva, el yachakuy nos ubica en el campo de la reflexión, allí donde el objeto de análisis es la propia conducta y el accionar dentro de un contexto, con la finalidad de construir una situación diferente que permita la convivencia con lo diverso y lo múltiple en otros términos que no sean las que mantienen la discriminación y exclusión.

Esta condición diádica de 'uno y otro' (yanantin) y sus relaciones asimétricas y desiguales son las que están en la base de la práctica ética o del yachakuy. Sin embargo, para las personas su vida social está también llena de satisfacciones que se derivan de las maneras peculiares de actuar en relación con el otro. Los amores (no costumbre) y las costumbres (regularidades) tienen matices, lo imprevisible y la rutinidad están presentes en esa condición diádica. En este ámbito también uno puede querer y el otro odiar; asimismo, el otro puede no entender el amor de uno y el uno no entender el odio del otro. Aun así, la relación persiste a pesar de la posibilidad de quedarse chulla (aislado, impar), que está siempre presente sobre la condición diádica. La ruptura es una amenaza y al mismo tiempo una realidad constante contra la que la cultura andina pelea, para que el aislamiento no se haga rutina y estructura.

\section{Convivo con lo diverso: imaymana kaswaykunawan yachanakuni}

En tercer lugar, los diferentes modos de vida hacen la pachamama. La historia la hacen todos los seres que viven en las coordenadas del tiempo y el espacio, en la historia, podríamos decir. En efecto, la biodiversidad que incluye al ser humano se puede describir como imaymana kawsaykuna. El 
término imaymana incluye 'todo' ${ }^{5}$, es semejante al holos griego, pues este término significa 'entero, todo, integro, completo, todas las cosas, diversas cosas o múltiples cosas'. Existe otro término quechua para decir diversidad y es ñawray, aunque este término - al parecer- ya no se suele usar en la actualidad. Entonces, el imaymana incluye en el ñawray (diversidad) a todos los elementos bióticos (miraqkuna) y abióticos (mana miraqkuna) ${ }^{6}$. El imaymana incluye las kawsaykuna, que no es sino el plural de la palabra vivir e incluye el conjunto de elementos existentes en la pachamama. Sin embargo, kawsay, que se puede traducir como 'vida', en la lengua quechua con término se designa al todo o la existencia en general y de manera específica abarca los elementos vinculados con la vida vegetal.

Entonces, en la pachamama no 'viven' los diversos elementos, sino estos 'conviven', es decir yachanakunku. El término es muy preciso y señala la profunda vinculación que hay entre los distintos existentes que comparten un mismo sistema (Depaz 2005). En este mundo, a los seres que no logran trasladarse por sus propios medios de un lugar a otro se les dice kawsaykuna. En cambio, los seres que pueden moverse por sí mismos son los uywakuna. Los seres humanos son también uywakuna porque requieren ser atendidos y cuidados de manera específica. Esto significa que los ñawray kawsaykuna conviven estrechamente y constituyen un sistema total o imaymana. En este terreno, el ser humano convive con otros porque es kawsaqniyuq. La diferencia entre la palabra kawsay y kawsaq es notable y no es posible confundir una con la otra; la primera señala la existencia de algo y la segunda indica específicamente la realidad del ser humano que tiene una energía vital diferente de los demás.

La pachamama está habitada por las diversas formas del existir, tales como los seres celestes, seres no visibles, cerros, animales, plantas y los seres humanos. Cada uno de los elementos recibe nombres según los lugares y las funciones que cumplen en cada grupo humano. En este sistema de manifestaciones de 'vida' todos contribuyen no solo a sostener la existencia sino a cuidar lo que los contiene. La vida (kawsay), entonces, es todo lo que contribuye al movimiento, a la autopoiesis del sistema mismo. En este contexto, cada uno de los elementos es corresponsable del conjunto y por lo tanto copartícipe de los acontecimientos que puedan ocurrir y también de las desgracias que se ocasionan.

\footnotetext{
5 También podría decirse lliw o llapam, que también significan 'todo' pero muy cercano a lo cuantificable; por ello, hemos preferido valernos del imaymana para mostrar la totalidad en términos cualitativos.

6 Estas dos expresiones son productos de un taller con profesores de Andahuaylas donde Víctor Palomino esbozó las concordancias entre las palabras castellanas y quechuas.
} 
Cada kawsay tiene una señal de su existencia en la pachamama y su capacidad de transformarse está vinculada al término ñawi (ojo). Este término significa, entre otros, 'punta de algo', el 'inicio o comienzo de algo', o simplemente 'ojo'. Cada elemento de la pachamama tiene su ñawi: en los animales son el par de órganos para mirar, en las plantas son las yemas, en las semillas son el germen, en las piedras son una de las puntas o un agujero, en el agua es el puquio, entre otros. El ojo (ñawi) es considerado como el lugar por donde la semilla, por ejemplo, puede comenzar a desarrollarse y orientar el movimiento del kawsay. No tener ojos es ser ñawsa o ciego. Las cosas que no tienen ojos tienden a morir y desaparecer. Esto indica que los ojos deben ser constantemente cuidados y atendidos en su proceso y desarrollo. Entonces, cada elemento existente es diferente por su propia constitución y su ñawi le hace ser de otra manera que los otros con quienes conviven.

Ahora bien, los miembros de la comunidad tienden a 'mirarse' permanentemente y a expresarse valiéndose de lenguajes diferentes. La condición diádica de los seres hace que el uno debe 'mirar' al otro, y esto equivale a saber cuidarlo, atenderlo considerando sus condiciones específicas. De la misma manera, el otro debe hacer igual con el uno. Estos roles conforman acciones para la complementariedad de las partes y al mismo tiempo muestran la ambigüedad de las relaciones. No siempre es claro para uno lo que hace el otro y viceversa, pues las acciones de unos y otros están siempre en el limbo y necesitan de la confianza para hacer el par o yananchakuy (hacerse pareja). Por lo tanto, la base de la ética en el mundo andino es esa condición compleja de creación de confianzas entre personas y entre la persona y la naturaleza, sabiendo que los componentes son diferentes y además buscan diferenciarse para establecer una condición de igualdad en la acción complementaria.

Las relaciones diádicas o yanantin son 'simples' pero también tienen una dimensión 'pública'. Es simple porque la regularidad de las relaciones indica que uno está indubitablemente plegado a otro por el solo hecho de habitar en cualquier lugar. El estar plegado al otro significa que las partes se implican mutuamente haciendo una dimensión compartida y que, entonces, es 'pública'. Por ello, lo que haga el uno repercute en el otro y viceversa en diversos grados; esto hace que no sea posible evadir las repercusiones positivas y negativas en esas relaciones. Cada cual es corresponsable de lo que realiza y la responsabilidad es la capacidad de responder por la acciones que cualquiera de las partes hace y repercute en el otro. Las repercusiones de las acciones lo disfrutan o lo padecen tanto los unos como los otros y son parte de la realidad de yachanakuy. 


\section{El hombre hace historia: runaqa pachamamapim ruran}

El hombre andino, en ese tiqsimuyu (mundo) hace historia en la medida en que se compromete en la construcción permanente de su propio entorno y de sí mismo. Es una tarea de «nunca acabar (mana tukuy)», pues los pobladores deben estar alertas a los cambios que se generan en el clima, pero también a los cambios que vienen de la modernidad. Hacer la historia es ruray; este ruray es lo que hace diferente al ser humano de los otros seres. Solo el ser humano puede 'hacer'. Este 'hacer' es vital porque expresa realizar, ejecutar, obrar, inventar, modificar entre otros significados. Ruray es más que llamkay, que se suele traducir como 'trabajar'. En todo caso, el ruray es aquella capacidad humana de convertir todos los campos en un espacio vivible y transitable para la convivencia social. Así, la historia no es sino el dominio del tiempo y del espacio en los que cada runa (persona o ser humano) puede sentirse realizado y runayasqa, vale decir, ser un ser renovado y nuevo. Por ello la historia para los andinos es la construcción de su propia manera de entenderse en la sociedad activando diversas relaciones.

La vida humana en los Andes es una interacción permanente con la naturaleza, con las comunidades de larga data, con los vecinos y las comunidades cercanas, con los visitantes y transeúntes de todas partes del mundo, a través de acciones conscientes que tienen diversas orientaciones. Aquellas acciones persiguen prioridades disímiles con resultados que pueden tener consecuencias benéficas o no. La persona diádica está vinculada con un mundo relativamente cerrado - para un observador externo- y al mismo tiempo abierto a lo amplio y complejo de la sociedad, desde el punto de vista de adentro. Las personas están intrínsecamente vinculadas con el cosmos y con todos los seres que habitan en su contexto social y cultural (como cualquier sociedad) y conforman su mundo. Ese mundo se conoce como tiqsimuyu pacha (universo, cosmos, mundo), en el que debe ser incluida la producción cultural de los seres humanos.

La vida humana en los Andes implica un campo semántico de relaciones complejas donde cada uno de los componentes diádicos está motivado por la presencia de la otra parte. El término genérico runa (ser humano) requiere de una precisión gramatical de género y para que no haya duda se señala la diferencia: warmi runa (mujer) y qari runa (varón), a esto hay que añadir si se trata de un warma (niño o niña) o machu o paya (persona de tercera edad varón o mujer) y también es kay llaqtamanta (de este pueblo) o hawa llaqtamanta (extranjero). Esta diversidad permite constituir de diferentes formas la manera de estar y vivir. La condición diádica, además, marca las vicisitudes históricas y cambiantes que no se pueden controlar de manera definitiva. La persona que es estructuralmente diferente dentro de la 
condición diádica hace que la historia cambie mediante el ruray (hacer). Este ruray es un elemento constitutivo del ser humano que genera cambios en la constitución de la vida social. ¿Qué tipo de ética es posible proponer desde esta condición?

La forma de vida se hace de manera compleja y es a la vez inacabada y en permanente proceso de cambio. En efecto, en la experiencia de las personas andinas su ser persona está en un proceso permanente de runayay (Calle et al. 2014) ${ }^{7}$; esto es, cada vez cada individuo busca hacerse persona o ciudadano a pesar de las condiciones asimétricas, desiguales y crueles (Rosset 1994) en las que vive y se desarrolla. Las relaciones sociales a menudo son crueles en tanto que la realidad vivida es dura y violenta (es cruda), y a la vez son relaciones que casi siempre implican dificultad y sufrimiento (relativo a doloroso). Sin embargo, las relaciones sociales tienen también un campo de simplicidad en el que a pesar de los obstáculos que se presentan inopinadamente es posible construir ventajas notables para vivir. Sabemos que las diversas formas de desigualdades que existen en la condición social están fracturadas por la economía, la política y también por alguna ideología que sustenta las diversas posiciones ante la vida. En este sentido, las relaciones humanas son asimétricas estructuralmente; pero esto no significa que sea un determinante que imposibilite la construcción de un imaginario común y de un espacio con-vivible con todos y la posibilidad de hacer tinkuypampa, pues esta palabra significa un espacio de encuentro de lo diverso.

Entonces, si la base sobre la que se elabora cualquier propuesta es la diferencia y la diversidad, entonces, ¿cómo pensar la ética desde esta condición? La cultura andina ha organizado su historia teniendo en cuenta la diversidad, lo imaymana o ñawraykuna; en efecto, la diversidad es un indeterminante y acicate a la cultura humana andina. Desde la geografía hasta la biología, la diversidad es una condición y, a lo largo de la historia andina, un reto para imaginar una sociedad diferente. El control y el dominio de esa diversidad tuvo que hacerse mediante la lucha constante, que se llama adaptación, y en el mundo quechua existen palabras para designar este proceso y situación: ratay y takyay. La primera significa 'acostumbramiento a algo', y la segunda es 'establecimiento después de un largo proceso de experimentación'. En este espacio habría que imaginar la 'unidad' como una interacción permanente de la diversidad y de la multiplicidad. Lo diverso

7 Runayay es runa-ya-y: esto significa que cuando a la raíz runa (persona, gente) se le añade el sufijo -ya (que indica proceso) que concluye con el infinitivo $-y$, el término significa que la persona está en proceso permanente de construcción de su misma identidad y su ser, diríamos con lenguaje moderno: proceso de construcción de la ciudadanía. 
supone que el otro es opuesto o diferente radicalmente y a la vez irreductible de la condición diádica: la alteridad (huk niraq), es distinto a uno.

Estar asentado en algún lugar supone, entre otros, ser usuario de un espacio físico habitable culturalmente; ser morador de una comarca y ser parte de un grupo humano con un nombre; saber que esa comunidad forma parte de una zona con un conjunto de familias con nombres; y estas comunidades forman de una región mayor. Entonces, una persona no habita solo en un lugar, habita con muchos otros de diversos nombres y formando una sociedad con historia y tradición, con prácticas particulares y sueños por construir, vale decir ruraspa (haciendo). Habitar en un lugar supone sembrar, cuidar y utilizar racionalmente el agua y la tierra, probar todos los elementos necesarios para vivir y gozar, pero también encontrarse en muchos niveles, practicando el tupay (encuentros inopinados), tinkuy («encuentro, junción de caminos, de cerro, ríos, etc. y no solo tiene referentes de naturaleza concreta, ya que además, significa concurrencia, ajuste de conceptos, comunión o coincidencia de ideas...»; Rodolfo Cerrón-Palomino) ${ }^{8}$ y el tinkiy (encuentros existenciales y vitales).

\section{En la vida el cuidado es mutuo: uywanakunam pachamamapiqa}

La adversidad y los tiempos difíciles (sasachakuy pacha) penden de un hilo en la experiencia de las poblaciones andinas urgidas por los fenómenos climatológicos como los friajes, las sequías o las inundaciones. Esto significa que los tiempos difíciles forman parte de las relaciones sociales que se han estructurado en modalidades coloniales expresadas en el abuso, la explotación, el engaño, la violación y la discriminación, entre otros; a esto hay que añadir las acciones devastadoras recientes como la contaminación del agua, de las tierras y la explotación irracional de los recursos naturales por una manera de enfocar el desarrollo. Aquellas 'adversidades' tienen implicancias sociales y políticas que se expresan en dos campos que no son fáciles de resolver. De una parte, en el campo económico y político donde está en disputa el modelo de desarrollo y las maneras de relacionarse con la naturaleza y, de otra parte, en el campo de las relaciones sociales y culturales donde se cuestiona la legitimidad de los actores sociales, sobre todo si provienen de los pueblos originarios. En suma, la adversidad que se hace presente entre nosotros, que es de origen antrópico, subraya ante todo el 'valor de cambio' que se le da a los

8 Texto que se encuentra en el edificio Tinkuy, lugar de encuentros de los estudiantes en el campus de la PUCP. 
elementos de la naturaleza mediante la sobre explotación y no toma en cuenta necesariamente el 'valor de uso' de los recursos para el que se requiere de una racionalidad cuidadosa.

Los andinos, a pesar del sasachakuy pacha de origen climático, económico y político desarrollan estrategias adaptativas a los cambios con un alto sentido de resiliencia. En este contexto, un conjunto de indeterminantes aparecen como amenazas en la vida de la gente y la naturaleza, como la escasez (muchuy), la vulnerabilidad (unquy), el asilamiento (chullayay) y la novedad de lo desconocido (chusaq). Estas amenazas, si bien son naturales, también tienen un origen humano, que pone en aprietos las relaciones humanas. Cuando esto ocurre, las poblaciones interpretan los cambios y las modificaciones de la naturaleza como una suerte de molestia o fastidio de la pachamama por el mal uso de su cuerpo. La 'madre tierra' se conmueve y se expresa con rabia o ira (piña) y se comporta como una 'madrastra'. ¿Qué significa estar piña? El término expresa la profunda 'molestia' que cualquiera siente por la transgresión de los límites y de sus derechos.

La lectura que los pobladores hacen de los cambios climatológicos y los desastres naturales está vinculada con las transformaciones de las relaciones económicas, sociales y políticas que afectan la producción y el consumo, sin ambages de los bienes. Los pobladores se dan cuenta, por ejemplo, que la presión que proviene del mercado es grande para la tierra, el agua y los seres vivientes de las localidades. La escasez de algunos productos en la familia local está vinculada a la demanda que hacen otras familias que provienen del mundo exterior. La respuesta que los agricultores utilizan para cubrir una demanda se vale de medios artificiales que no cuidan necesariamente, por ejemplo, del proceso natural de maduración de los productos agrícolas. Entonces, cuando alguien dice que la tierra está con ira (piña), no es extraño que se exprese mediante eventos que desequilibran el sistema, y este se manifiesta en precariedades que ponen en peligro la seguridad ecológica y alimentaria de los pobladores.

El comportamiento estratégico andino solo pretende vincularse con cuanta persona visite su espacio. Esto supone que el cuidado que tiene del otro también implica el propio cuidado. Estos comportamientos, sin embargo, son interpretados como una actitud estoica, de aguante, resistencia o rebelión, según los casos. Los pobladores andinos solo elaboran estrategias para entender las distintas formas de presencia de diversos elementos externos que buscan colonizar y controlar su vida cotidiana. Buscan entenderlos con la finalidad de incorporarlos en su proceso social, pero también mantener cierta distancia cuando hay cosas no se aceptan. En efecto, la tolerancia, al parecer, es la forma más sutil para tratar a los que incluso van con buenas intenciones de colaboración o ayuda. 
El conflicto y la paz son cíclicos en la vida social y en las interacciones personales bajo diversas manifestaciones. El conflicto es una relación social que vincula a dos actores que se oponen argumentando razones diferentes y designa «cualquier relación de elementos que puedan caracterizarse por una oposición de tipo objetivo (latente) o subjetivo (manifiesto)» (Darendorf 1966: 184). La paz es también una relación social en la que los actores construyen un acuerdo para mantener un vínculo que no atente la autonomía de las partes de manea temporal.

En estas condiciones los pobladores ubican su pensamiento y sus acciones en una relación explícitamente interdependiente mediante el uywanakuy o el cuidado mutuo. En este contexto, cuidar (uyway) es una forma de relación de ida y vuelta. El ser humano desde su propia ubicación es cuidante de la naturaleza (arariwa), no su propietario. Por lo general el andino entiende que lo que está a su alcance en la naturaleza no es suyo; se comporta más bien como usuario y lo hace de manera cíclica. El usuario de lo que existe debe saber cuidarlo y no puede disponer para enajenarlo o deshacerse. Sin embargo, la influencia de la modernidad ha generado otras maneras de relacionarse con la naturaleza, por ejemplo las tierras se venden a los mejores postores para cubrir la lógica perversa del lucro; las tierras recibidas en herencia en la actualidad tienen precios solo accesibles a los intereses de los inversionistas que ven ventajas comparativas para hacerse de los terrenos de los más pobres.

Aun así, el cuidado de la naturaleza y de su cultura se levanta como una bandera de identidad local y regional. Los andinos siguen el consejo de sus propias maneras de adaptarse en sociedades económicas y políticas agresivas. La defensa de las tierras se hace solo con lo que tienen: la vida. El cuidad o de la tierra es el cuidado de su propia seguridad y salud social. De esas tierras dependen los kawsaykuna y los uywakuna en sus diversos estados: uywasqakuna (domesticados) o sallqa, purum y kita (no domesticados). El hombre andino sabe que las cosas están ahí y tienen el derecho a estar en ese lugar sin ser molestadas (piñachisqa) y para ello debe solo acceder valiéndose de una pedagogía cultivada milenariamente que se denomina yupaychakuy, esto es la manera de tomar contacto con la naturaleza a través de rituales que reflejan lo que algunos conocen como agradecimiento y respeto. El agradecimiento y el respeto son solo dos maneras del uywanakuy, es decir, del mutuo cuidado en el marco de la convivencia. Por estas razones Córdova dice:

En este proceso, la crianza (uywanakuy) es un aspecto relevante que involucra a la naturaleza y las personas para vigorizar la armonía practicada en los Andes con relación a chakranchik uyway (crianza de nuestras chacras), uywanchik uyway (crianza 
de nuestros animales), sallqanchik uyway (crianza de lo silvestre), runamasinchikwan uywanakuyninchik (crianza entre seres humanos), yakunchik uyway (crianza y cuidado de nuestro agua), wayranchik uyway (crianza de nuestro aire y viento) y todo cuanto es necesario en nuestras relaciones interpersonales como en algunas experiencias recogidas en páginas anteriores (Córdova 2004: 26).

Cada poblador, entonces, trata de cuidar su espacio y lo que hay en este, porque ese espacio es entendido como algo que está bajo su responsabilidad y también un logro personal, vale decir, un don que se mantiene a través de formas rituales de agradecimiento. Así como cada cual debe cuidar su espacio, del mismo modo debe cuidar el de los otros para evitar determinados conflictos. Los más pobres en los Andes buscan vivir sin dejar de reconocer que la vida que tienen no es independiente respecto de la pachamama a donde pertenecen y que, además, no están necesariamente desvinculados del Estado o el mercado a pesar de sus abandonos y sus desventajas. Las necesidades los hacen actuar colaborativamente en diversas acciones con la única finalidad de no ser excluidos de probables beneficios, por más ínfimos que sean.

El poblador andino cuida el entorno en el que habita, cuida su tierra mediante su familia o ayllu. Esta es una forma de organización social que vincula a los seres humanos y a los otros elementos de la naturaleza y de la historia. Hoy en día se sigue diciendo tayta inti y mama killa al sol y a la luna, respectivamente, para sostener una alianza familiar amplia; las canciones hablan de las estrellas como las hermanitas; perotambién semenciona al tayta urqu y la mamapacha, como también a la mamaqucha. Todos forman parte de una unidad mayor. Las maneras de acercarse a estos elementos indican que se trata de vínculos diferenciados y - al decir de algunos- se trata de formas de respeto que se establecen con la trascendencia, tan presentes en la vida social andina. El ayllu vela por el individuo y su realización de manera autónoma, pero el individuo no siempre busca la realización del ayllu.

\section{El cuidado mutuo es una responsabilidad: uywanakuyqa nanachikuymi}

La conciencia de pertenencia y el cuidado del medioambiente en el que la persona andina vive se tornan en una exigencia ética. Esto no significa que todas las relaciones con el medioambiente sean vínculos que tiendan a proteger los recursos naturales. Diversas actividades sociales y culturales no son un ejemplo para la defensa de la biodiversidad. Asimismo, las personas 
que no viven de manera permanente en un entorno natural tienden a considerar este espacio con un sentido utilitarista y exotizante que no favorece necesariamente el cuidado de esos espacios.

Pero la actitud que está en la experiencia andina es la que hace prevalecer el cuidado de todo lo que está a su alrededor y a esta actitud se le dice nanachikuy. Este término tiene una particular implicancia para la ética y se puede traducir como 'responsabilizarse-del-otro-por parte de-uno'. Es conveniente reflexionar sobre el sentido de la palabra y las implicancias sociales y éticas del término en contextos concretos. El término está compuesto de una raíz y un conjunto de sufijos que se pueden seccionar para el análisis de la siguiente manera: nana-chi-ku-y. Veamos por partes: nana es una raíz que puede ser traducida de varias maneras: 'dolor', 'dolencia', 'sacrificio', 'carga', 'obligación'; -chi es un sufijo causativo que indica 'hacer que el otro haga algo', por ejemplo mikuchiy significa: «Haz que el otro coma o dale de comer al otro» (Zariquiey y Córdova 2008: 171); el sufijo -ku es reflexivo, que significa que la acción realizada por un sujeto recae sobre sí mismo (2008: 170), como por ejemplo purikuy, que significa 'caminar para uno mismo; y e -y es la terminación del verbo en infinitivo.

Ahora bien, si digo nanachikuypim kachkani, se puede traducir simplemente como 'estoy con responsabilidades o en medio de responsabilidades', esto significa que la persona tiene entre manos una tarea que debe sostener y cumplir a cabalidad. La raíz nanay implica una tarea que ha sido asumida voluntariamente y por ello le compete al sujeto 'cargar' aquello con el que se ha comprometido y debe tomarlo hasta su cumplimento definitivo. Es un deber. Quizá por ello el verbo nanay significa también 'dolor' y 'sacrificio', porque aquello que se busca obtener implica necesariamente una cuota de esfuerzo. La tarea tiene de todas maneras una parte molestosa que consiste en el peso que se debe cargar hasta liberarse de este cuando haya cumplido su ciclo o su realización.

Entonces, ¿qué significa la responsabilidad en el mundo andino? La responsabilidad implica la relación intrínseca de las personas como ayllu o comunidad. La alteridad o el huknin (otro) forman parte de una unidad diádica que está entrelazada lingüísticamente por el sufijo -ntin. El mundo social es inextricablemente ayllu donde el otro y el uno no pueden separarse ontológicamente, pues el ser humano es huknintin. Esto implica que la amenaza de la división o partición (chullayay) no cesa y es a la vez una realidad que es resuelta siempre mediante el aylluchakuy o la alianza con los otros en diversos grados y de diversas maneras.

¿Qué pasa cuando una metodología basada en la racionalidad del sujeto o del individuo se pone en contacto con esta manera de pensar? El conflicto y las formas de dominación son evidentes y sus resultados son nocivos, sobre todo para una de las partes que no tiene argumentos basados en una 
racionalidad instrumental. Lo que representa esa racionalidad instrumental está dicho por Celina en la película de Salvador del Solar: Magallanes. Al final de la película Celina, una joven ayacuchana que había sido violentada por miembros del Ejército durante la época de violencia política, los reconoce y en una circunstancia determinada les dice:

Dinero... qullqi, qamkunapa umaykichikpi qullqillam. ¿Chay qullqiwanchu ñuqataqa hampirquwankichik llapa rurawasqaykichikta? ¿Mamayta taytaytachu kawsarichimunkichik kay qullqiwan? Puntata munasqaykichikta ñuqawan rurarqankichik. Derechoykunata saruparqankichik. ¿Imatataq kaypi kachkani? ¿Imapaqtaq kaypi kachkani? ¿Haykapikamam suyasaq? Derechoykunatam sarupachkankichik kunanpas. Manañam manchakuykichikchu qamkunataqa; ni qamta, ni payta, ni pita... ¿Me puedo retirar? (Del Solar 2015).

[Dinero... dinero, en su mente solo hay dinero, ¿Acaso con ese dinero van a reparar todo lo me han hecho? ¿Acaso con ese dinero van a hace revivir a mi padre y a mi madre? Antes han hecho lo que han querido conmigo. Han pisoteado mis derechos. ¿Qué hago aquí? ${ }^{9}$ ¿Para qué estoy aquí? ¿Hasta cuándo voy a esperar? Incluso ahora están pisoteando mis derechos. Ahora ya no les tengo miedo; ni a ti, ni a él, ni a nadie... ¿Me puedo retirar?] [traducción del autor].

Si la unidad implica la diversidad, entonces las relaciones entre las partes son siempre asimétricas y además buscan un tinkuy en el campo de la socialización y su garantía en el tiempo. Los pobladores del mundo andino también buscan la igualdad, la que es un anhelo basado sobre todo en la redistribución de las obligaciones que se derivan de esas relaciones. En este sentido, en esa redistribución el otro es la referencia de uno y no al revés. Por ejemplo, cuando uno quiere saber el nombre del otro, se hace en plural: «ipitaq kachkanchik? (quiénes somos)», la respuesta es también a menudo en plural: «Manuelmi kachkanchik (somos Manuel)». En la actualidad se ha buscado simplificar el uso del plural para valerse del singular al traducir del castellano al quechua y diciendo así: «¿imataq sutiyki? (qué es tu nombre)»; de esta manera no se pregunta por la persona sino por el nombre de esa persona. Subrepticiamente, entonces, la asimetría social puede ser avalada tácitamente y ser naturalizada en formas de discriminación mediante algunas 'afirmaciones culturales'.

Entonces, la responsabilidad no evita la asimetría, antes bien la enfrenta mediante 'el compromiso-de-uno-mismo-para-con-el-otro que me 
está esperando permanentemente'. La responsabilidad o nanachikuy es una conducta y una relación social que responde a las demandas permanentes de las necesidades del otro. Ser responsable es sobre todo atender y cuidar al otro que forma parte de mi estructura social comunitaria. La madre o el padre no deberían abandonar a sus hijos porque su responsabilidad consiste en cuidar a los débiles y a esto se llama uyway. Pues una uywa es alguien o algo 'creado' al que se debe atendery 'criar' hasta que pueda desenvolverse por sus propias fuerzas. Por ello, crear y criar son dos expresiones indesligables del nanachikuy. De ocurrir dichas separación, la debacle se cierne amenazante hasta que los vínculos se logran restablecer de varias maneras.

La demanda del uyway no se puede eludir, pues se trata de una estructura social mínima para ser y vivir. El cuidar es el gesto que trasciende las relaciones egoístas o chullayay, vale decir que se opone a la pretensión de aislarse o quedarse solo, sin su par o su pareja. El uyway se presenta como un mandato ético porque si uno quiere vivir no puede hacerlo abandonando al otro; de lo contrario, la estructura social podría resentirse y lo humano se resquebrajaría. En este sentido, la interpretación comunitaria de las relaciones con la naturaleza va en esta dirección: «Si no cuidas a la pachamama, la pachamama te puede castigar». Esta sentencia debe ser interpretada como una advertencia antes que una superstición, pues considerando un razonamiento lógico se puede decir que si hay algo de lo que eres responsable y no lo haces correctamente, las consecuencias de la desidia pueden acarrear resultados dañosos y graves.

Entonces, nanachikuy es una categoría que expresa la estructura moral de una sociedad que hace del uyway (cuidar) una relación permanente. Es esta una de las maneras de definir la 'responsabilidad-de-uno-paracon-el-otro', allí reside el sentido de lo humano pues hay que dolerse y compadecerse por el otro y estar presente haciendo lo que se debe hacer para fortalecer los vínculos sociales y hacer que el ayllu siga siendo el modo de 'convivencialidad', que los seres humanos reclaman cuando se dan cuenta que están solos en varios sentidos. Para que haya 'convivencialidad' debe considerarse la multidimensionalidad de lo humano y todo aquello que se requiere para ir en esa dirección. Por ejemplo, Illich dice: «Llamo sociedad convivencial a aquella en que la herramienta moderna está al servicio de la persona integrada a la colectividad y no al servicio de un cuerpo de especialistas. Convivencial es la sociedad en la que el hombre controla la herramienta» (1975: 13). La mentalidad instrumental sigue reduciendo el desarrollo solo al crecimiento económico, lo que se vale de todo lo demás solo para fines lucrativos.

Para resumir, tal parece que en el mundo andino el término nanachikuy fue perdiendo fuerza por, entre otras razones, la movilidad poblacional y el cambio tecnológico que han modificado inextricablemente la condición de la 
comunidad o el ayllu. La modernidad ha colocado a los pobladores del Ande en una nueva condición social y económica. La racionalidad del mercado ha invadido y ha desarrollado el sentido de la competencia y el éxito. Entonces, de qué nanachikuy podemos hablar en nuevas situaciones. El sentido de la responsabilidad cambia pero la naturaleza de esta no. El ser humano sigue siendo comunidad y en nuevas condiciones, donde la tecnología ejerce primacía sobre lo humano, se replantea la necesidad de cuidar su medio y sus relaciones para seguir considerando su realización y su propio destino. Tal vez una de las señales más importantes del deseo de responsabilidad de la comunidad para con el crecimiento adecuado del niño se da a través del suñay, que consiste en el regalo que un adulto da a un niño. El regalo es siempre una cría de un animal doméstico con el siguiente mensaje: «Toma este regalo, es tuyo, cuídalo responsablemente y será de mucho provecho para ti cuando hayas crecido; de paso, practica y desarrolla tu manera de vincularte con la naturaleza y la sociedad».

\section{Vivir bien para estar en paz: Allinta kawsana hawka kanapaq}

La ética es simple porque se trata de una relación cotidiana y permanente; pero es también compleja cuando aquella relación cotidiana es a la vez asimétrica, desigual y diferenciada. Es asimétrica por la composición de los que forman la relación social, puesto que cada parte está marcada por una tradición, su propia cultura y por sus proyectos locales. Es desigual porque las condiciones sociales han ido configurándose por una distribución diferenciada que ha convertido ideológicamente la injusticia en algo natural, conformando una estructura con diferencias económicas y políticas; la desigualdad puede lacerar las sensibilidades pero también cambiar y desarrollarse en otra dirección. Y es diferenciada porque los roles que desempeñan los individuos se ejercen en el marco de una estructura jerárquica y estamental en medio de relaciones de poder. Estas relaciones diferenciadas hacen que los individuos tengan preferencias y elijan los campos de sus relaciones para no intervenir en otros ni ser interferidos por los otros.

Llegado a este punto, queremos dedicar algunas reflexiones a una expresión quechua que suelo escuchar: "Allintam kawsana hawka kanapaq (hay que vivir bien para tener la paz)». En primer lugar, allintam kawsana es un condicional que significa 'hay que vivir bien'. El sentido de la expresión tiene sentido si se sabe qué es 'vivir bien' y esto se logra con algunos satisfactores como alimentación, autonomía, familia y participación, entre otros. El vivir bien implica tener, entonces, buena salud, tener una familia relativamente estable, que no haya desconciertos por eventos de diferente 
origen y magnitud, entre otros. Para que ocurra esto el ser humano necesita hacer lo que debe con prolijidad (allin ruray), vincular las diferencias de manera lúdica (pukllay), atender y cuidar todo lo que se usa y está con nosotros (uyway), convidar o distribuir tanto lo bienes como los servicios (aypukakuy), agradecer por todo lo que un recibe en la vida (yupaychay).

El 'vivir bien', entonces, no consiste en una declaración sino requiere de acciones concretas que deben manifestarse en la vida cotidiana y ser realizadas a través de rituales festivos en diversas etapas del ciclo anual. En todo caso, 'vivir bien' es sentirse realizado haciendo lo que corresponde, distribuir lo que se tiene, vincularse socialmente según sea necesario. Los sentimientos y los vínculos son la condición real para estar 'viviendo bien'. Aquellas relaciones afectan de hecho la densidad de las relaciones y el mantenimiento de dichas relaciones. En una estructura históricamente desigualy diferenciadora, las relaciones devienen discriminantes y las débiles relaciones de confianza se resquebrajan y abren brechas insondables. El vivir bien es compartir las vicisitudes sociales, que se recuerda en una canción: «Ruraqman chayaspa, rurapakuna; / mikuqman chayaspa, mikupakuna; / tusukman chayaspa tusupakuna». Una traducción de estos versos sería: «Si arribas donde están trabajando, hay que participar del hacer; / Si arribas donde están comiendo, hay que participar de la comida; / Si arribas donde hay baile; hay que participar del baile» (Muñoz 2014: 26).

Además, vivir bien en un lugar es saber compartir lo que uno tiene para hacer probar y saborear (malliy) el producto de uno con el otro. Esta simple acción es una forma de redistribución en medio de las familias y los vecinos, quienes invitan de lo suyo para que conozcan y saboreen lo que han producido en el año. Del mismo modo, la seguridad social y ciudadana está ordenada por un conjunto de patrones de protección, para lo que se valen de sistemas organizativos, normas y reglamentos internos no siempre escritos. En este contexto, las personas siempre agradecen (yupaychay) por la vida, por lo que se recibe, por la amistad y la parentela que, en última instancia, sigue siendo la referencia social de seguridad. De ahí que yupaychay signifique 'honrar, respetar y reverenciar a divinidades o a personas'. Los pobladores siempre estarán agradecidos por cada día que pasa y lo celebran de muchas maneras.

En segundo lugar, hawka kankapaq se puede traducir como 'para estar en paz'. Esta es la máxima aspiración en la vida de las personas. Las personas no buscan allin kawsay sino allin kay y aquí el verbo kay es sinónimo de 'estar', 'ser' y 'sentir'. El allin kay es la condición para desear y anhelar de manera permanente el hawka kay. La estabilidad emocional, social, económica, religiosa y política puede, entonces, incorporarse en la categoría hawka, que consiste en tener una vida en paz producto de la justicia, pues 
nadie puede vivir tranquilo si no tiene lo necesario (medios y relaciones) para desarrollarse como individuo o como comunidad. En efecto, no se puede estar tranquilo o en paz si la familia no tiene lo necesario para la vida. La paz o tranquilidad es una experiencia personal y comunitaria que es el resultado de la confluencia de varios elementos tales como: haber hecho bien las cosas y con resultados evidentes, haber contado con el cuidado y haber contribuido del mismo modo para la paz local, haber distribuido parte de sus bienes a través de rituales sociales con la participación de la población, entre otros.

Entonces, si se señala «allinta kawsana hawka kanapaq» es para decir 'si vives haciendo bien las cosas, la paz estará ahí' o quizás 'hay que vivir bien para estar en paz'. En cualquiera de las dos formas el objetivo final es dar testimonio de la estabilidad integral o total de las personas en la comunidad. Creo que este es el sentido de la ética en el mundo andino: lograr la paz comunitaria que debe pasar por el desarrollo integral de la persona en todos los campos. La paz no es quietud, sino el resultado del flujo constante de acciones que las personas realizan para lograr la igualdad, la justicia y la tranquilidad para todos los miembros de la comunidad. Entonces, los versos de una joven puneña tienen sentido cuando dice: «Extraño mi otra mitad / ese complemento / que solía hacerme reír / o darme más cólera / extraño ese pedacito de mi alma / extraño esas manitas / que con un abrazo / calman este vacío que ahora siento / como los extraño / mis hermanos (...)» (Jeny, joven universitaria). No podrá estar hawka mientras esté lejos de sus parientes aunque esté allin donde esté.

\section{Referencias}

Calle, Efraín et al. (2011) Ama usuchisqa kanapaq, runayananchikpaq. Para ser ciudadanos y no ser discriminados. Lima: PUCP.

Córdova, Gavina (2004) «No le Enseñan Las Cosas Para Pasar La Vida, Sólo le Enseñan a Leer y a Escribir" Reflexiones sobre la escuela». Center for Latin American Social Policy (CLASPO). <http://lanic.utexas.edu/project /etext/llilas/claspo/ rtc/0059.pdf>.

DARENDORF, RAlF (1966). Sociedad y libertad. Hacia un análisis sociológico de la actualidad. Madrid: Tecnos.

Del Solar, SAlvador (Director y guionista) (2015). Magallanes. Filme cinematográfico. Coproducción Péndulo Films / Tondero Films / Cepa Audiovisual / Proyectil / Cinerama Ltda.

DePAZ, ZENón (2005). «Horizonte de sentido en la cultura andina. El mito y los límites del discurso racional». En: Peña, Antonio et al. La racionalidad andina. Lima: Editorial Mantaro; pp. 47-76. 
EsCalante, CARMEn y Ricardo VAlDERRAma (1992). Nosotros los humanos. Testimonio de los quechuas del siglo XX. Ñuqanchik runakuna. Cusco: CBC.

Estermann, Josef (1998). La filosofía andina. Quito. Abya-Yala.

ILLICH, IvÁN (1975). La convivencialidad. Barcelona: Seix Barral.

LeVinas, Emmanuel (1991). Ética e infinito. Madrid: Visor.

MuÑoz, Urbano (2014). Filosofía andina y otros temas quechuas. Lima: Altazor.

Rosset, ClÉment (1994). El principio de crueldad. Trad. R. del Hierro. Valencia: PreTextos.

Sobrevilla, DAvid (2008). «La filosofía andina del P. Josef Estermann». Solar, № 4, año 4, Lima; pp. 231-247.

YANEz, José (2002). Yanantin: la filosofía dialógica intercultural del manuscrito de Huarochirí. Quito: Abya-Yala.

ZARIQUIEY, ROBERTO Y GAVINA CóRdova (2008).Q ayna, kunan, paqarin. Una introducción práctica al quechua chanca. Colección Intertextos N. ${ }^{\circ}$ 3. Lima: PUCP. 